\title{
Multi-trait meta-analyses reveal 25 quantitative trait loci for economically important traits in Brown Swiss cattle
}

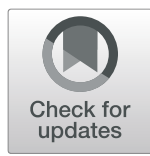

\author{
Zih-Hua Fang ${ }^{*}$ (D) and Hubert Pausch
}

\begin{abstract}
Background: Little is known about the genetic architecture of economically important traits in Brown Swiss cattle because only few genome-wide association studies (GWAS) have been carried out in this breed. Moreover, most GWAS have been performed for single traits, thus not providing detailed insights into potentially existing pleiotropic effects of trait-associated loci.

Results: To compile a comprehensive catalogue of large-effect quantitative trait loci (QTL) segregating in Brown Swiss cattle, we carried out association tests between partially imputed genotypes at 598,016 SNPs and daughterderived phenotypes for more than 50 economically important traits, including milk production, growth and carcass quality, body conformation, reproduction and calving traits in 4578 artificial insemination bulls from two cohorts of Brown Swiss cattle (Austrian-German and Swiss populations). Across-cohort multi-trait meta-analyses of the results from the single-trait GWAS revealed 25 quantitative trait loci ( $Q T L ; P<8.36 \times 10^{-8}$ ) for economically relevant traits on 17 Bos taurus autosomes (BTA). Evidence of pleiotropy was detected at five QTL located on BTA5, 6, 17, 21 and 25. Of these, two QTL at BTA6:90,486,780 and BTA25:1,455,150 affect a diverse range of economically important traits, including traits related to body conformation, calving, longevity and milking speed. Furthermore, the QTL at BTA6:90,486,780 seems to be a target of ongoing selection as evidenced by an integrated haplotype score of 2.49 and significant changes in allele frequency over the past 25 years, whereas either no or only weak evidence of selection was detected at all other QTL.

Conclusions: Our findings provide a comprehensive overview of QTL segregating in Brown Swiss cattle. Detected QTL explain between 2 and 10\% of the variation in the estimated breeding values and thus may be considered as the most important QTL segregating in the Brown Swiss cattle breed. Multi-trait association testing boosts the power to detect pleiotropic QTL and assesses the full spectrum of phenotypes that are affected by trait-associated variants.
\end{abstract}

Keywords: Selection, Pleiotropy, Genome-wide association study, Runs of homozygosity, Extended haplotype homozygosity

\section{Background}

Genome-wide association studies (GWAS) between economically important traits and dense single nucleotide polymorphism (SNP) genotypes identified hundreds of quantitative trait loci (QTL) and thousands of trait-associated genetic variants in many cattle breeds [1]. Prioritizing trait-associated variants in

\footnotetext{
* Correspondence: zih-hua.fang@usys.ethz.ch

Animal Genomics, Institute of Agricultural Science, ETH Zürich, 8092 Zürich, Switzerland
}

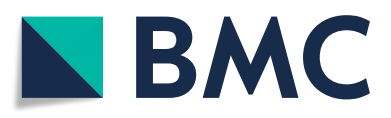

(๑) The Author(s). 2019 Open Access This article is distributed under the terms of the Creative Commons Attribution 4.0 International License (http://creativecommons.org/licenses/by/4.0/), which permits unrestricted use, distribution, and reproduction in any medium, provided you give appropriate credit to the original author(s) and the source, provide a link to the Creative Commons license, and indicate if changes were made. The Creative Commons Public Domain Dedication waiver (http://creativecommons.org/publicdomain/zero/1.0/) applies to the data made available in this article, unless otherwise stated.

genomic prediction models may accelerate genetic gain, particularly when large reference populations are not available, e.g., for traits that are either expensive or difficult to measure [2]. Furthermore, characterizing the spectrum of traits that are affected by pleiotropic QTL may contribute to a better understanding of the physiological underpinnings of economically important traits and help unravelling molecular-genetic mechanism through which QTL acts. This knowledge could further facilitate an improved prediction 
of correlated responses given selection for particular traits [3].

Natural or artificial selection changes the frequency of variants underpinning the traits under selection and their neighboring polymorphic sites in linkage disequilibrium. Strong selection may result in regions of extended homozygosity along the genome, i.e., selective sweeps (see review [4]). Detecting such patterns could provide insight into responses of the cattle genome to past and ongoing natural and artificial selection and reveal loci and variants that underpin adaptive and economically important traits [5], thus enhancing our understanding of genetic mechanisms controlling phenotypes under selection $[6,7]$.

The Brown Swiss cattle breed is popular in many European countries including Austria, Germany and Switzerland. Brown Swiss cows produce high milk and protein yields and have a long productive life under various production and environmental conditions. However, the genetic architecture of these traits is not well characterized in Brown Swiss cattle since only few GWAS were carried out so far in this breed [8-11]. Because most of the association studies performed so far considered either only one trait at a time or were restricted to clusters of related traits, detecting QTL that are associated with seemingly unrelated traits was not possible in those studies and the extent to which pleiotropic QTL contribute to trait variation and correlation in Brown Swiss cattle is currently unknown.

In this study, we performed GWAS for more than 50 economically important traits, including milk production, body conformation, carcass quality, and functional traits (reproduction, health and management), in Brown Swiss cattle. Our aim was to detect the most important QTL that underpin these economically important traits and investigate if the detected QTL showed pleiotropic effects or evidence of recent or ongoing selection.

\section{Results}

We considered 4578 Brown Swiss bulls from Austrian-German and Swiss populations that had estimated breeding values (EBVs) for 56 economically important traits (Additional file 1: Table S1) for our analyses. A total of 99 cohort-specific single-trait GWAS (44 traits in Austrian-German and 55 traits in Swiss population, see Additional file 1: Table S1 for more information about the traits considered) revealed a total of 1067 significant $\left(P<8.36 \times 10^{-8}\right)$ trait $x$ SNP associations. Of these, 648 and 305 SNPs were significantly associated with one and two traits, respectively, and 114 SNPs were significantly associated with at least three traits (Additional file 2: Figure S1), suggesting that pleiotropic effects are present and detectable in the studied populations.
Summary of QTL effects and candidate genes by different categories of traits

To increase the power of the association tests and characterize pleiotropic QTL, we carried out multi-trait meta-analyses with traits classified into 11 trait categories (referred to as trait-cat meta-analyses). These 11 trait-cat meta-analyses revealed a total of 1203 SNPs that were significantly associated in at least one multitrait meta-analysis, thus increasing by $13 \%$ the number of significantly associated SNPs compared to the singletrait GWAS. By grouping significant SNPs located within $5 \mathrm{Mb}$ of the lead SNP, we identified between zero (somatic cell score and lactation persistency) and seven QTL (milk production) for the trait-cat meta-analyses. These QTL are characterized in more detail below separately for the trait categories considered (Fig. 1 and Table 1).

\section{Milk production}

We detected seven QTL $\left(P<8.36 \times 10^{-8}\right)$ that were associated with milk production traits on seven different chromosomes in Brown Swiss cattle. Of these, four QTL were significantly associated with multiple traits in the single-trait GWAS: a QTL on BTA5 was associated with five traits, and three QTL on BTA6, 14 and 20 were associated with two traits (Table 1). Five of seven milk production QTL encompass genes that had previously been reported to affect milk yield or content in cattle, including the MGST1 gene on BTA5 [11, 12], the cluster of casein genes on BTA6 [13], the PAEP (also known as $\beta$-lactoglobulin) gene on BTA11, the GHR gene on BTA20 [14] and the AGPAT6 gene on BTA27 [15]. Note that the gene next to the lead SNP (rs133636599, at 29, 987,376 bp) on BTA20 was not GHR but MRPS30 encoding mitochondrial ribosomal protein $\mathrm{S30}$, which we did not consider as an obvious candidate gene explaining variation in milk production traits. The GHR gene encoding the growth hormone receptor was considered as a plausible candidate gene for the QTL on BTA20 because significantly associated SNPs were detected between 29.9 and $34.8 \mathrm{Mb}$. This region coincided with a previously reported QTL for milk production traits in Brown Swiss cattle, where the GHR p.F279Y-variant [14] was the most significantly associated variant [11].

Another two QTL for milk production traits were located on BTA14 and BTA16. Both regions have recently been described to harbor QTL for milk production traits in several cattle breeds including Brown Swiss [11, 16, 17]. The well-known DGAT1 p.A232K-variant [18] can be excluded as the causal variant for the milk production QTL on BTA14 because it does not segregate in Brown Swiss cattle [11], but mutations in DGAT1 other than the p.A232K-variant might segregate in Brown Swiss. Additionally, for a QTL for milk production traits in 
a

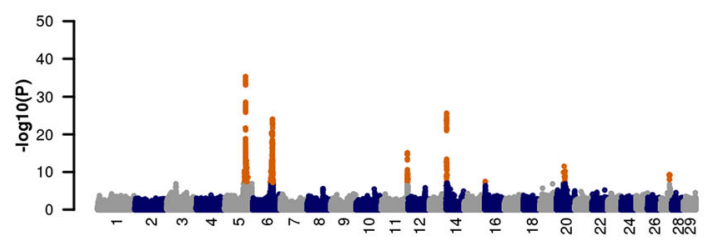

Chromosome

C

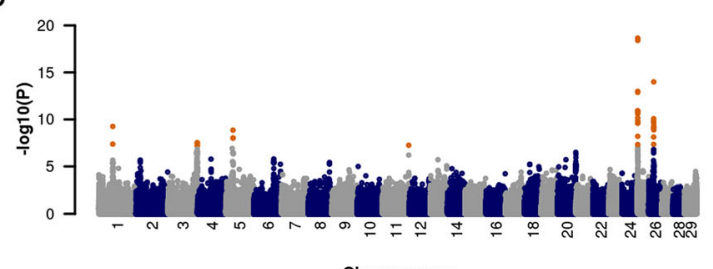

e

Fertility

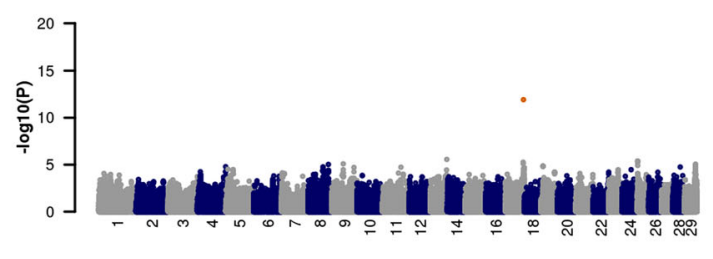

Chromosome

g

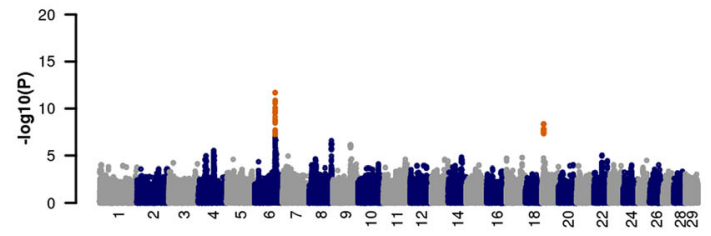

Chromosome

i

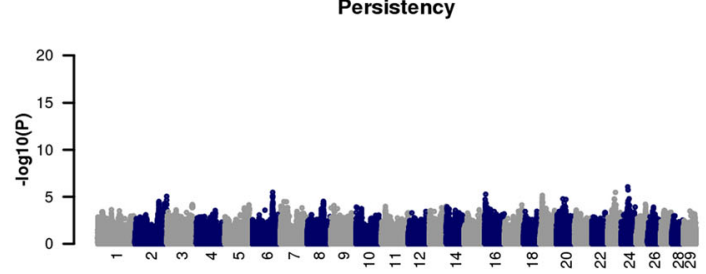

Chromosome

k

Calving

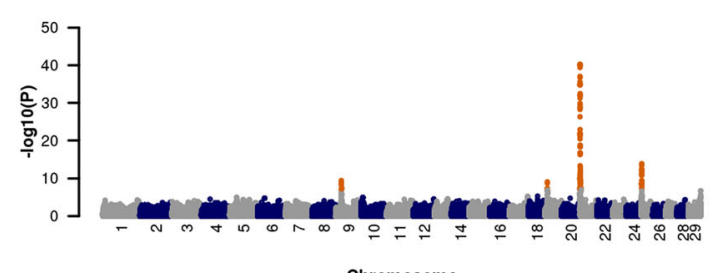

b

Mammary gland morphology

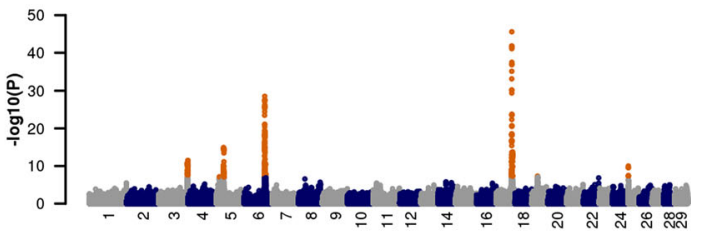

Chromosome

d

Leg conformation

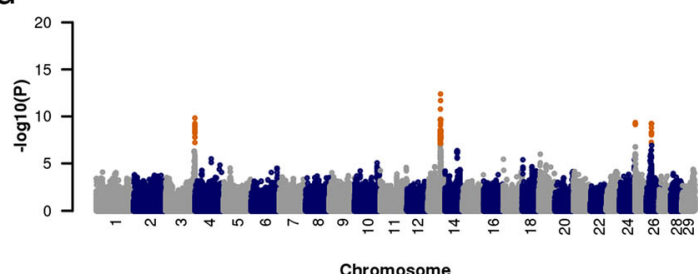

f

Growth and carcass quality

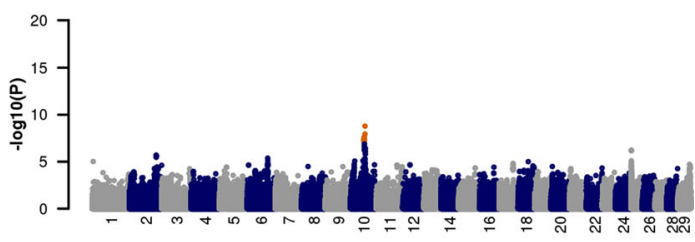

Chromosome

h

Longevity

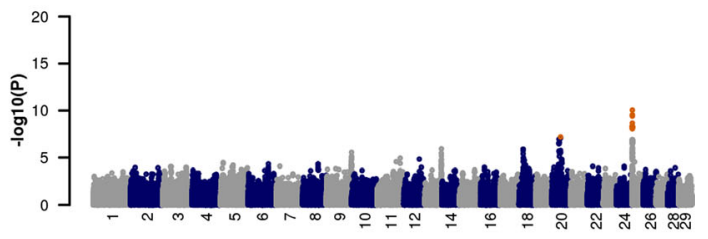

Chromosome

j

Somatic cell score

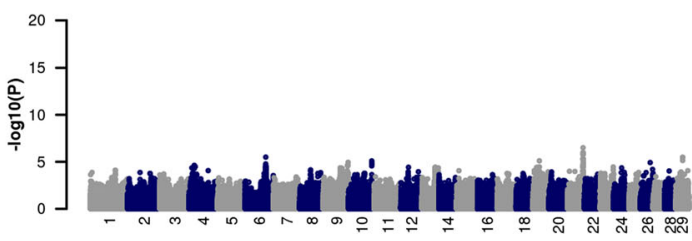

Chromosome

I

99-trait meta-analysis

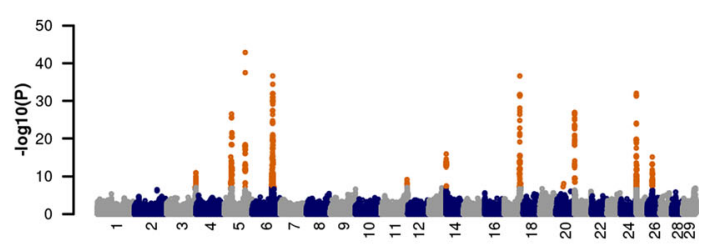

Fig. 1 Manhattan plots for 11 trait-cat meta-analyses and 99-trait meta-analysis. Manhattan plot representing the association of 598,016

autosomal SNPS. Orange color represents variants with a P PETA less than $8.36 \times 10^{-8}$. The $y$-axis for the milk production meta-analysis was cut off at $-\log 10(P)=50$ 
Table 1 The most significant SNP at QTL detected across trait-cat meta-analyses and potential candidate genes

\begin{tabular}{|c|c|c|c|c|c|c|c|c|}
\hline Trait category & BTA & Position (bp) & RefSNP id & Annotation & MAF & $P$ value & $\mathrm{N}$ of traits & Candidate gene(s) \\
\hline \multirow[t]{7}{*}{ Milk production } & 5 & $93,945,655$ & rs134637616 & Intron & 0.26 & $3.26 \times 10^{-67}$ & 5 & MGST1 \\
\hline & 6 & $87,172,459$ & rs109761275 & Intergenic & 0.30 & $1.35 \times 10^{-24}$ & 2 & Casein genes \\
\hline & 11 & $103,302,351$ & rs110186753 & Intron & 0.33 & $7.47 \times 10^{-16}$ & 1 & PAEP \\
\hline & 14 & $2,538,953$ & rs109673915 & Intron & 0.20 & $2.29 \times 10^{-26}$ & 2 & GPIHBP1 \\
\hline & $16^{\mathrm{d}}$ & $1,588,321$ & rs109375222 & Intergenic & 0.41 & $3.07 \times 10^{-8}$ & 1 & - \\
\hline & 20 & $29,987,376$ & rs133636599 & Intergenic & 0.14 & $2.97 \times 10^{-12}$ & 2 & GHR \\
\hline & $27^{d}$ & $36,274,982$ & rs133883836 & Intergenic & 0.23 & $5.91 \times 10^{-10}$ & 1 & AGPAT6 \\
\hline \multirow[t]{4}{*}{ Body size } & $1^{d}$ & $59,332,879$ & rs137415420 & Intron & 0.34 & $5.57 \times 10^{-10}$ & 0 & DRD3 \\
\hline & 3 & $120,159,650$ & rs42818065 & Intergenic & 0.35 & $2.90 \times 10^{-8}$ & 0 & - \\
\hline & $11^{d}$ & $104,496,081$ & rs110574932 & Intron & 0.07 & $5.63 \times 10^{-8}$ & 0 & $D B H$ \\
\hline & 26 & $22,133,617$ & rs42088986 & Intron & 0.24 & $1.00 \times 10^{-14}$ & 1 & BTRC \\
\hline \multirow[t]{3}{*}{ Leg conformation } & 3 & $120,211,603$ & rs109854637 & Intergenic & 0.34 & $1.48 \times 10^{-10}$ & 0 & - \\
\hline & $13^{d}$ & $60,593,663$ & rs110597649 & Intergenic & 0.16 & $4.13 \times 10^{-13}$ & 2 & $\mathrm{RSPO4}$ \\
\hline & 26 & $22,717,514$ & rs134127590 & Intergenic & 0.31 & $5.92 \times 10^{-10}$ & 1 & BTRC \\
\hline \multirow[t]{5}{*}{ Mammary gland morphology } & 3 & $120,265,990$ & rs136664568 & Downstream gene & 0.33 & $3.44 \times 10^{-12}$ & 2 & - \\
\hline & $5^{d}$ & $12,507,199$ & rs110171876 & Intron & 0.08 & $7.22 \times 10^{-8}$ & 0 & TMTC2 \\
\hline & 6 & $90,631,225$ & rs133549245 & Upstream gene & 0.27 & $2.94 \times 10^{-29}$ & 2 & RASSF6 \\
\hline & 17 & $62,697,699$ & rs137563207 & Intergenic & 0.24 & $2.62 \times 10^{-46}$ & 9 & TBX5, RBM19 \\
\hline & $19^{d}$ & $23,233,071$ & rs41584904 & Downstream gene & 0.10 & $4.97 \times 10^{-8}$ & 0 & PITPNA \\
\hline \multirow[t]{2}{*}{ Body conformation (shared) } & 5 & $31,524,629$ & rs110940367 & Downstream gene & 0.36 & $\begin{array}{l}a_{1} .39 \times 10^{-9} \\
c_{1} .20 \times 10^{-15}\end{array}$ & $\begin{array}{l}0 \\
2\end{array}$ & - \\
\hline & 25 & $1,455,150$ & rs133315098 & Intergenic & 0.44 & $\begin{array}{l}{ }^{\mathrm{a}} 2.22 \times 10^{-19} \\
{ }^{\mathrm{b}} 4.47 \times 10^{-10} \\
{ }^{\mathrm{c}} 1.00 \times 10^{-10}\end{array}$ & $\begin{array}{l}6 \\
0 \\
0\end{array}$ & IGFALS \\
\hline Fertility & $17^{d}$ & $70,735,784$ & rs136040855 & 3' UTR & 0.14 & $1.22 \times 10^{-12}$ & 2 & GAS2L1, ASCC2 \\
\hline \multirow[t]{4}{*}{ Calving } & $9^{d}$ & $24,850,498$ & rs42227651 & Intergenic & 0.17 & $3.54 \times 10^{-10}$ & 0 & RSPO3 \\
\hline & $19^{d}$ & $9,600,700$ & rs136348444 & Intron & 0.09 & $7.92 \times 10^{-10}$ & 1 & - \\
\hline & 21 & 913,715 & rs108992215 & Intergenic & 0.15 & $5.49 \times 10^{-41}$ & 2 & MAGEL2 \\
\hline & 25 & $1,489,008$ & rs109557202 & Intron & 0.44 & $1.48 \times 10^{-14}$ & 3 & IGFALS \\
\hline Growth and carcass quality & $10^{d}$ & $59,164,533$ & rs43636323 & Intergenic & 0.34 & $1.65 \times 10^{-9}$ & 0 & CYP19A1 \\
\hline \multirow[t]{2}{*}{ Milking speed } & 6 & $90,443,733$ & rs133851432 & Intergenic & 0.26 & $1.96 \times 10^{-12}$ & 1 & RASSF6 \\
\hline & $19^{d}$ & $7,610,453$ & rs110598898 & Downstream gene & 0.20 & $4.32 \times 10^{-9}$ & 1 & - \\
\hline \multirow[t]{2}{*}{ Longevity } & $20^{d}$ & $34,160,944$ & rs135463978 & Intergenic & 0.26 & $6.43 \times 10^{-8}$ & 0 & - \\
\hline & 25 & $1,455,150$ & rs133315098 & Intergenic & 0.44 & $8.90 \times 10^{-11}$ & 1 & IGFALS \\
\hline
\end{tabular}

The positions of the QTL correspond to the UMD3.1 assembly of the bovine genome

BTA Bos Taurus autosome

$M A F$ minor allele frequency

RefSNP id Reference SNP ID

$N$ of traits Number of significant single-trait associations

${ }^{a} P$ value for body size

${ }^{\text {b }} P$ value for leg conformation

c $P$ value for mammary gland morphology

${ }^{d}$ marks QTL missed in the 99-trait meta-analysis

close vicinity to DGAT1 on BTA14, the GPIHBP1 gene has been postulated as candidate gene $[17,19]$.

\section{Body conformation}

A total of 60 traits related to body conformation (30 traits for each cohort) were classified into three categories as body size, leg conformation and mammary gland morphology. The respective three trait-cat meta analyses revealed six, four and seven QTL that were associated with body size, leg conformation and mammary gland morphology, respectively (Fig.1; Table 1). Of six QTL associated with body size, four (QTL on BTA1, 3, 5 and 11) were not 
significantly associated with any of the 99 traits in the single-trait GWAS. A QTL on BTA25 was associated with six traits related to body size, and a QTL on BTA26 was associated with one trait related to body size in the singletrait GWAS. Of four QTL associated with leg conformation, two (QTL on BTA3 and 25) were not detected in the single-trait GWAS. QTL on BTA3 and 25. Two QTL on BTA13 and 26 were associated with two and one trait(s) related to leg conformation, respectively. Of seven QTL associated with mammary gland morphology, three were not detected in single-trait GWAS including QTL at BTA5:12,507,199, BTA19 and BTA25. A QTL for mammary gland morphology on BTA17 was significantly associated with nine traits related to the shape of the mammary gland, and three QTL were associated with two traits.

Among the 17 QTL detected for three categories related to body conformation, four QTL on BTA3, 5, 25 and 26 were significant for more than one trait category. A QTL for body confirmation traits was located on BTA3. Significantly associated SNPs were detected in an interval between 117.3 and $120.2 \mathrm{Mb}$. This QTL was associated with body size $\left(P=2.90 \times 10^{-8}\right)$, leg confirmation $(P=1.48 \times$ $\left.10^{-10}\right)$ and mammary gland morphology $\left(P=3.44 \times 10^{-}\right.$ ${ }^{12}$ ). The lead SNPs differed for the three trait categories but were in very high linkage disequilibrium (LD; $0.93<$ $\mathrm{r}^{2}<0.97$ ). This region coincides with a QTL for stature that has been detected in various cattle breeds [20]. A total of 12 annotated genes were located within a 1-Mb interval centered on the lead SNPs at this QTL. However, we did not observe an obvious candidate gene that might explain variation in body conformation traits.

Another QTL for body confirmation traits was located on BTA5 with significantly associated SNPs being located between 29.9 and $31.5 \mathrm{Mb}$. This QTL was associated with body size $\left(P=1.39 \times 10^{-9}\right)$ and mammary gland morphology $\left(P=1.20 \times 10^{-15}\right)$, and the same SNP was the lead SNP (rs110940367 at 31,524, $629 \mathrm{bp}$ ) for both trait categories. A total of 25 genes were annotated within $1 \mathrm{Mb}$ of the lead SNP, including 11 protein-coding genes. However, none of the genes had obvious functions related to growth or mammary gland development.

A QTL for body conformation was located at the proximal region of BTA25, and the same SNP (rs133315098 at 1,455,150 bp) was the lead SNP for all three trait categories related to body conformation $(P=$ $2.22 \times 10^{-19}$ for body size; $P=4.47 \times 10^{-10}$ for leg conformation; $P=1.00 \times 10^{-10}$ for mammary gland morphology). This region had been previously shown to be associated with stature in Brown Swiss cattle [8]. A total of 68 annotated genes located within $1 \mathrm{Mb}$ of the lead SNP, including 51 protein-coding genes. The gene closest to the lead SNP was $M E I O B$ encoding the meiosis specific protein with $\mathrm{OB}$ function (19 KB upstream of the transcription start), which we did not consider as an obvious candidate gene for body conformation traits because this gene is mainly involved in meiotic recombination [21]. A potential candidate gene mapped to this region was IGFALS encoding insulin-like growth factor binding protein acid labile subunit, of which the lead SNP is located at about $87 \mathrm{~KB}$ upstream of the transcription start. Variation in the IGFALS gene has previously been shown to affect growth-related traits in human and mouse [22].

Another QTL for body confirmation was located on BTA26 with significantly associated SNPs located between 21.6 and $22.7 \mathrm{Mb}$. It was associated with body size $\left(P=1.00 \times 10^{-14}\right)$ and leg conformation $\left(P=5.92 \times 10^{-}\right.$ $\left.{ }^{10}\right)$. The lead SNPs differed between two trait categories but were in high LD $\left(r^{2}=0.70\right)$. So far, this region has not been reported to affect body conformation traits in cattle. A total of 22 genes were annotated within $1 \mathrm{Mb}$ of the lead SNPs, including 20 protein-coding genes. The lead SNP for body size (rs42088986 at 22,133,617 bp) was located within the third intron of $B T R C$ encoding a member of the F-box protein family. This gene is involved in Wnt signaling that plays a critical role in developmental processes and has been shown to be associated with limb development [23] and limb abnormalities [24].

Apart from QTL that were associated with several trait categories related to body conformation, we detected six trait-cat specific QTL including two QTL on BTA1 and 11 for body size, one QTL on BTA13 for leg conformation, and three QTL on BTA6, 17 and 19 for mammary gland morphology. These regions have previously been associated with various body conformation traits in several cattle breeds including Brown Swiss [9, 20, 25-27].

\section{Reproduction (fertility and calving)}

A QTL $\left(P=1.22 \times 10^{-12}\right)$ on BTA17 was associated with two fertility-related traits: interval from first to last insemination and non-return rate in heifers. This QTL was also significant in the fertility meta-analysis. An association between genetic variants in this region and fertility has been reported previously in Brown Swiss cattle [10]. The lead SNP (rs136040855 at 70,735,784 bp) was located at the 3'UTR of the AP1B1 gene encoding adaptor related protein complex 1 subunit beta 1 , which we did not consider as a plausible candidate gene for fertility. A previous study revealed that two missense variants located in the GAS2L1 gene encoding growth arrest specific 2 like 1 (at 70,724,328 bp) and $A S C C 2$ gene encoding activating signal cointegrator 1 complex subunit 2 (at 71,084,044 bp) segregate in Brown Swiss cattle, and the variant in $A S C C 2$ gene has been suggested as a 
plausible candidate causal mutation controlling female fertility in cattle [10].

Four QTL on BTA9 $\left(P=3.54 \times 10^{-10}\right), 19(P=7.92 \times$ $\left.10^{-10}\right), 21 \quad\left(P=5.49 \times 10^{-41}\right)$ and $25\left(P=1.48 \times 10^{-14}\right)$ were associated in a meta-analysis of traits related to the calving performance. Three QTL on BTA19, 21 and 25 were significant in one, two and three single-trait GWAS, respectively. Variants nearby these regions have been shown to be associated with calving traits either in Brown Swiss or Fleckvieh cattle [10, 28, 29]. A QTL for calving traits on BTA9 was significant in the trait-cat meta-analysis but not in the single-trait GWAS. This region has not been reported so far to be associated with calving performance in cattle. Four genes were annotated within $1 \mathrm{Mb}$ of the lead SNP (rs42227651 at 24, $850,498 \mathrm{bp}$ ), including two protein-coding genes. The RSPO3 gene, of which the lead SNP was located approximately $0.5 \mathrm{Mb}$ downstream of the transcription end, might be considered as a potential candidate gene that might explain variation in calving traits. This gene encodes R-spondin 3 which modulates WNT signaling [30] and is involved in blood vessel formation including placental development, which could affect fetal growth and thus result in calving difficulties [31].

\section{Growth and carcass quality}

The trait-cat meta-analysis revealed a QTL $(P=1.65 \times$ $10^{-9}$ ) on BTA10 that was associated with growth traits and carcass quality. This QTL was not significant in the single-trait GWAS. The lead SNP (rs43636323) was located between the GLDN gene encoding gliomedin (about $33 \mathrm{~KB}$ upstream of the transcription start) and the CYP19A1 gene encoding cytochrome P450, family 19 , subfamily A, polypeptide 1 (about $63 \mathrm{~KB}$ upstream of the transcription start). A QTL for carcass traits and growth index in Holstein and Red Dairy cattle is located in immediate vicinity of the lead SNP and CYP19A1 gene was considered as the candidate gene because it catalyzes the conversion of androgens to estrogens [32]. Variation in the CYP19A1 gene is associated with both growth and reproduction in mice and humans [33, 34].

\section{Management (milking speed and longevity)}

We detected two QTL on BTA6 $\left(P=1.96 \times 10^{-12}\right)$ and $19\left(P=4.32 \times 10^{-9}\right)$ for milking speed and two QTL on BTA20 $\left(P=6.43 \times 10^{-8}\right)$ and $25\left(P=8.90 \times 10^{-11}\right)$ for longevity (Fig.1 and Table 1). The QTL on BTA6 and 25 were also associated with body conformation traits (described above). The lead SNP of a longevity QTL on BTA25 was also the lead SNP for body conformation traits. A QTL $\left(P=4.32 \times 10^{-9}\right)$ for milking speed on BTA19 coincides with a QTL for milking speed in Nordic Holstein [35]. Ten genes were annotated within 1 $\mathrm{Mb}$ of the lead SNP (rs110598898 at 7,610,453 bp), including seven protein-coding genes. However, we did not detect an obvious candidate gene related to milking speed. A QTL $\left(P=6.43 \times 10^{-8}\right)$ for longevity was located on BTA20 at about $34 \mathrm{Mb}$. This QTL was not detected in the single-trait GWAS. However, we did not observe an obvious candidate gene that might explain variation in longevity.

\section{Overview of QTL segregating in Brown Swiss cattle}

In an attempt to compile an overview of major QTL segregating in Brown Swiss cattle, we performed a multitrait meta-analysis combining the results of all 99 cohort-specific single-trait GWAS. The 99-trait meta-analysis revealed 531 significantly associated SNPs that clustered at 12 QTL $\left(P<8.36 \times 10^{-8}\right)$ regions on BTA3, $5,6,11,14,17,20,21,25$ and 26 . When compared to the trait-category based meta-analyses, the 99-trait meta-analysis did not reveal any new QTL (Fig. 1) and less than half the number of SNPs were significantly associated. Moreover, 13 QTL that were detected in at least one trait-cat meta-analysis were not significantly associated in the 99-trait meta-analysis (Table 1). The maximum proportion of EBV variance explained by the QTL detected in 99-trait meta-analysis across traits ranged from 0.02 for the QTL on BTA11 to 0.10 for the QTL at BTA5:93,945,655 both for fat percentage (Table 2).

Of these 12 detected QTL, five, six and one were associated with milk production, body conformation and calving performance, respectively (Table 2). The 99-trait meta-analysis enabled us to distinguish between two neighboring QTL on BTA6: a QTL at BTA6:87,005,244 associated with milk production traits and a QTL at BTA6: 90,486,780 associated with mammary gland morphology and milking speed (Additional file 3: Figure S2). Compared to the trait-cat meta-analyses, the lead SNPs of the 99-trait meta-analysis differed for two QTL on BTA6 and one QTL on BTA14. The lead SNP at BTA6:87005244 in the 99-trait meta-analysis was about $0.17 \mathrm{MB}$ apart from the one for milk production (at 87, $172,459 \mathrm{bp})$, but they were in moderate LD $\left(\mathrm{r}^{2}=0.41\right)$. The lead SNP at BTA6:9048678 in the 99-trait metaanalysis was located between the lead SNPs for milking speed (at 90,443,733 bp) and mammary gland morphology (at 90,631,225 bp). These three SNPs were in moderate LD $\left(0.51<\mathrm{r}^{2}<0.70\right)$. The lead SNP at a QTL on BTA14 (at 2,534,899 bp) in the 99-trait meta-analysis was about $4 \mathrm{~Kb}$ distant from the lead SNP of the milk production (at 2,538,953 bp), but they were in high LD $\left(r^{2}=0.75\right)$. Furthermore, four QTL that were detected in more than one trait-cat meta-analysis including QTL at BTA5:31524629, BTA6:90,486,780, BTA25:1,455,150 and BTA26:22,133,617, had lower $P$ values in the 99-trait meta-analysis than any of the trait-cat meta-analyses, 
Table 2 The properties of 12 QTL detected in the 99-trait meta-analysis

\begin{tabular}{|c|c|c|c|c|c|c|c|c|c|c|c|}
\hline BTA & $\begin{array}{l}\text { Position } \\
\text { (bp) }\end{array}$ & RefSNP id & Annotation & MAF & $\begin{array}{l}\text { Effect } \\
\text { allele }\end{array}$ & $\begin{array}{l}\text { Ancestral } \\
\text { allele }\end{array}$ & $P$ value & $V_{E B V}$ & $i \mathrm{HS}$ & Trait category & $\begin{array}{l}\text { Candidate } \\
\text { gene(s) }\end{array}$ \\
\hline 3 & $\begin{array}{l}120,211 \\
603\end{array}$ & rs109854637 & Intergenic & 0.34 & A & A & $\frac{1.02 \times 10}{-11}$ & 0.028 & - & body conformation & - \\
\hline 5 & $\begin{array}{l}31,524 \\
629\end{array}$ & rs110940367 & $\begin{array}{l}\text { Downstream } \\
\text { gene }\end{array}$ & 0.36 & G & G & $\begin{array}{l}3.18 \times \\
10^{-27}\end{array}$ & 0.030 & -1.65 & body conformation & - \\
\hline 5 & $\begin{array}{l}93,945 \\
655\end{array}$ & rs134637616 & Intron & 0.26 & C & C & $\begin{array}{l}1.35 \times \\
10^{-43}\end{array}$ & 0.128 & 1.35 & milk production & MGST1 \\
\hline 6 & $\begin{array}{l}87,005 \\
244\end{array}$ & rs135679764 & Intron & 0.18 & G & - & $\begin{array}{l}1.87 \times \\
10^{-15}\end{array}$ & 0.041 & - & milk production & Casein genes \\
\hline 6 & $\begin{array}{l}90,486 \\
780\end{array}$ & rs41654962 & Intergenic & 0.20 & G & G & $\begin{array}{l}2.35 \times \\
10^{-37}\end{array}$ & 0.088 & 2.49 & $\begin{array}{l}\text { body conformation, } \\
\text { milking speed }\end{array}$ & RASSF6 \\
\hline 11 & $\begin{array}{l}103,302 \\
351\end{array}$ & rs110186753 & Intron & 0.33 & G & - & $\begin{array}{l}6.64 \times \\
10^{-10}\end{array}$ & 0.020 & - & milk production & PAEP \\
\hline 14 & $2,534,899$ & rs109673915 & Intron & 0.25 & G & G & $\begin{array}{l}1.33 \times \\
10^{-16}\end{array}$ & 0.045 & - & milk production & GPIHBP1 \\
\hline 17 & $\begin{array}{l}62,697 \\
699\end{array}$ & rs137563207 & Intergenic & 0.24 & C & C & $\begin{array}{l}2.35 \times \\
10^{-37}\end{array}$ & 0.042 & 0.19 & body conformation & TBX5, RBM19 \\
\hline 20 & $\begin{array}{l}29,987 \\
376\end{array}$ & rs133636599 & Intergenic & 0.14 & A & C & $\begin{array}{l}8.24 \times \\
10^{-9}\end{array}$ & 0.033 & 1.21 & milk production & $G H R$ \\
\hline 21 & 913,715 & rs108992215 & Intergenic & 0.15 & A & - & $\begin{array}{l}1.30 \times \\
10^{-27}\end{array}$ & 0.042 & - & calving & MAGEL2 \\
\hline 25 & $1,455,150$ & rs133315098 & Intergenic & 0.44 & A & A & $\begin{array}{l}9.72 \times \\
10^{-33}\end{array}$ & 0.046 & - & $\begin{array}{l}\text { body conformation, calving, } \\
\text { longevity }\end{array}$ & IGFALS \\
\hline 26 & $\begin{array}{l}22,133 \\
617\end{array}$ & rs42088986 & Intron & 0.24 & A & A & $\begin{array}{l}8.59 \times \\
10^{-16}\end{array}$ & 0.035 & -0.57 & body conformation & BTRC \\
\hline
\end{tabular}

The positions of the QTL correspond to the UMD3.1 assembly of the bovine genome

BTA Bos Taurus autosome

$M A F$ minor allele frequency

RefSNP id Reference SNP ID

$V_{E B V}$ maximum proportion of the variance in estimated breeding value (EBV) explained by the QTL across traits

Trait category Trait group with which the QTL were associated

iHS integrated haplotype score (not available for SNPs located at the beginning and the end of the chromosome)

- not available

whereas all other QTL that were significant for only one trait category had higher $P$ value in the 99-trait metaanalysis than any of the trait-cat meta-analyses (Tables 1 and 2).

Two QTL (at BTA6:90,486,780 and BTA25:1,455,150) were shared across different trait categories that were not related to body conformation (Table 2). The QTL on BTA6 was associated with mammary gland morphology and milking speed. The $G$ allele of the lead SNP (rs41654962) had a frequency of 0.8 in Brown Swiss cattle. It was associated with thinner teats and reduced milking speed (Table 2; Additional file 4: Table S2). The QTL on BTA25 was associated with body size, leg confirmation, mammary gland morphology, calving ease and longevity. The $A$ allele of the lead SNP (rs133315098) had a frequency of 0.56 and was associated with high birth weight (both direct and maternal), larger stature and longer gestation length. It was also associated with calving difficulties (both direct and maternal), greater stillbirth incidence and reduced longevity (Table 2 and Additional file 5: Figure S3).

\section{Selection signatures}

Genome-wide scans of selection signatures

Regions on BTA4, 5, 6, 11, 16 and 19 harbored runs of homozygosity $(\mathrm{ROH})$ that were frequent in Brown Swiss cattle. However, the lead SNPs of QTL detected from 99-trait meta-analysis were rarely located in $\mathrm{ROH}$ that were shared across individuals except for the ones on BTA6 and 25 (Fig. 2).

We calculated integrated haplotype scores (iHS) for each SNP to detect ongoing selection at alleles that have not yet reached fixation. Negative and positive iHS values indicate selection for derived and ancestral alleles, respectively. Evidence of strong selection $(P<$ 0.001 ) was found for genomic regions on BTA5, 6, 12, 13, 14, 15, 16, 19 and 24 (Fig. 2), including five regions on BTA5, 6, 12, 16 and 19 that were previously detected in a smaller sample of Brown Swiss cattle [36]. The lead SNPs of QTL detected in the 99-trait meta-analysis did not coincide with candidate regions of selection signature except for the lead SNP at BTA6:90,486,780. Ten SNPs on BTA6 (located 

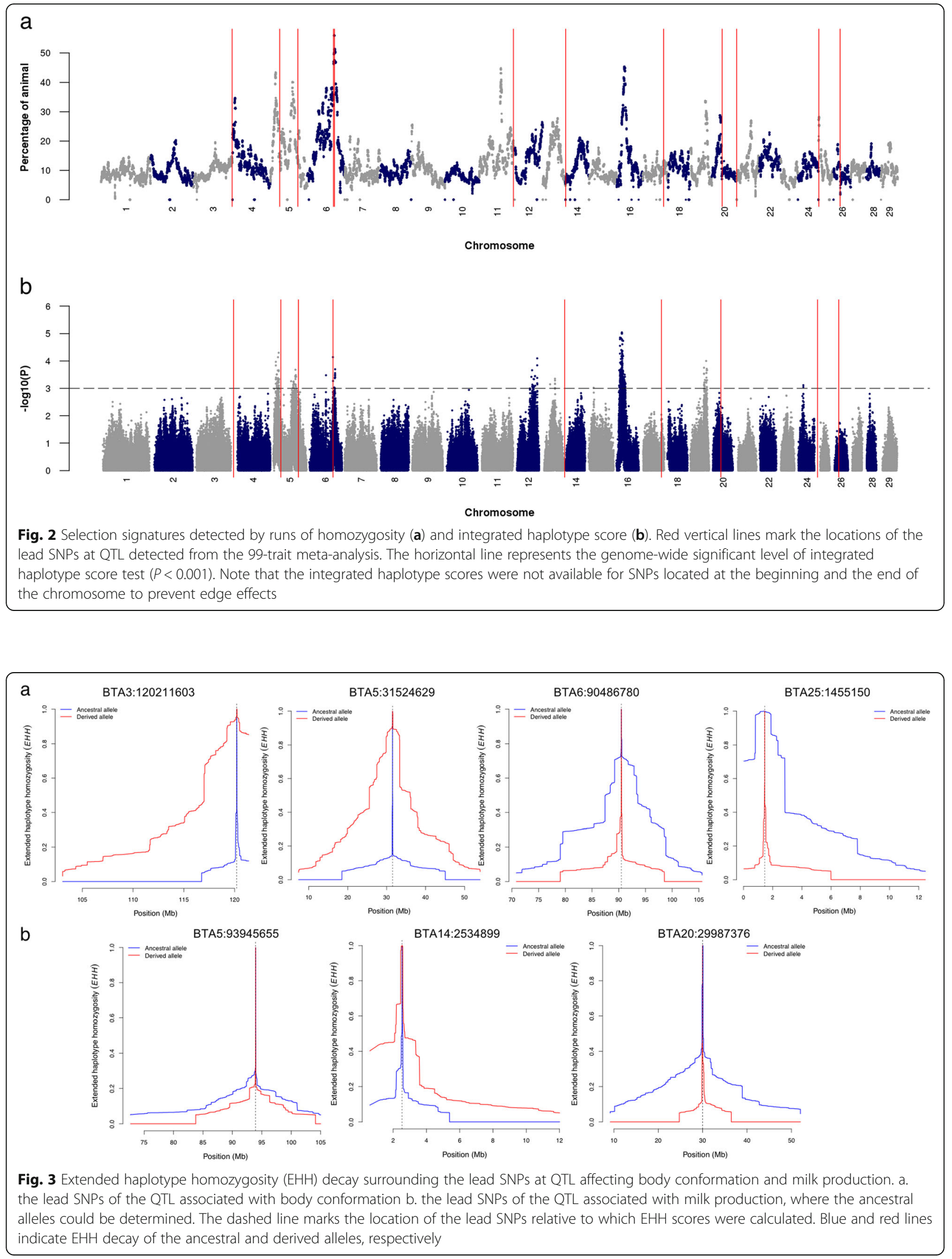
between 90.2 and $91.7 \mathrm{Mb}$ ) were significant both in the 99-trait meta-analysis and iHS test. Note that iHS values were not calculated for SNPs located either at the proximal or distal regions of chromosomes to prevent edge effects [37].

\section{Signatures of selection at the lead SNPs of the multi-trait meta-analysis}

Derived and ancestral alleles could be determined for the lead SNPs at nine out of 12 QTL detected in the 99-trait meta-analysis. Generally, all lead SNPs showed either no or only weak evidence of selection because most of their corresponding $|\mathrm{iHS}|$ values were less than 1.98 (Table 2). However, the $|\mathrm{iHS}|$ value was 2.49 for the lead SNP at BTA6:90,486,780 that was associated with mammary gland morphology and milking speed, suggesting that this QTL is a target of ongoing selection. A positive iHS value at the lead SNP indicates selection for the ancestral allele that was associated with thinner teats and reduced milking speed (Additional file 4: Table S2). This is also shown by a slower extended haplotype homozygosity (EHH) decay over the distance surrounding the ancestral allele than the derived allele of this SNP (Fig. 3).

Of three lead SNPs (BTA5:31,524,629, BTA5:93,945,655 and BTA20:29,987,376) that showed weak evidence of selection $(|\mathrm{iHS}|>1)$, the lead SNP at BTA5:31,524,629 that was associated with body size and mammary gland morphology showed a markedly different decay of haplotype homozygosity surrounding the ancestral and derived alleles
(Fig. 3). Among three lead SNPs (BTA3:120,211,603, BTA14:2,534,899 and BTA25:1,455,150) that were located in proximal and distal regions of chromosomes, the lead SNP at BTA3:120,211,603 and BTA25:1,455,150 that were associated with body conformation also showed difference in decay of haplotype homozygosity surrounding the ancestral and derived alleles compared to the lead SNP at BTA14:2,534,899 that was associated with milk production (Fig. 3). The alleles at BTA3:120,211,603, BTA5:31,524,629 and BTA25:1,455,150 that increased body size showed slower EHH decay over distance than the alleles with the opposite effects (Fig. 3; Additional file 4: Table S2).

Six out of 12 lead SNPs detected in 99-trait meta-analysis showed significant changes $\left(P_{\text {Bonferroni-corrected }}<0.05\right)$ in their allele frequencies from birth year 1990 to 2015 (Fig. 4). Out of these six lead SNPs, four were associated with body conformation traits. The alleles that increased in frequency over time were associated either with larger body size or thinner teats (Additional file 4: Table S2). The other two lead SNPs were associated with milk production, and the alleles that increased in frequency over time were associated with higher protein and fat percentage (Additional file 4: Table S2).

\section{Discussion}

We performed single-trait GWAS between partly imputed genotypes at 598,016 SNPs and 99 daughter-derived phenotypes for economically important traits in 4578 Brown Swiss bulls from Austria, Germany and

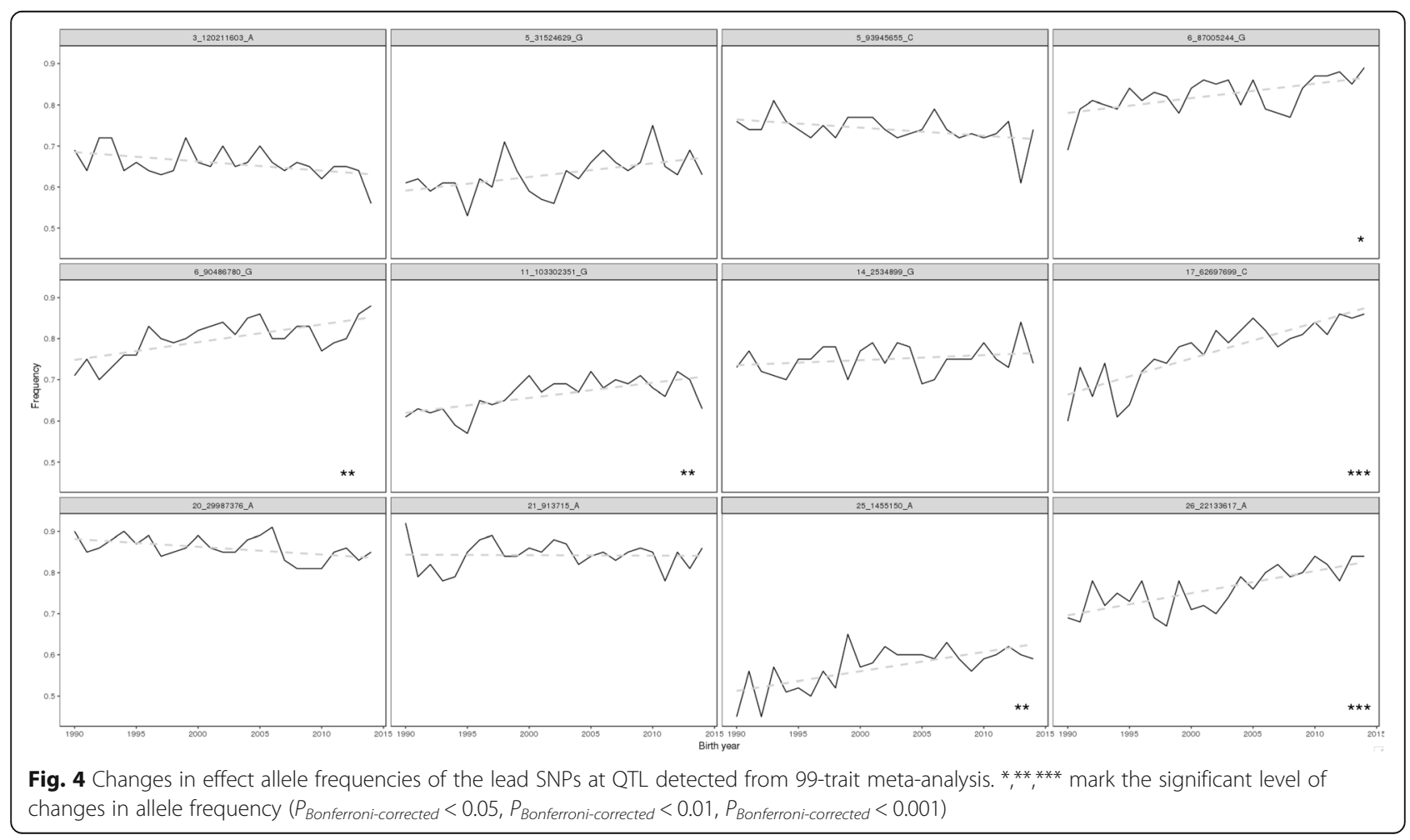


Switzerland. Subsequently, we performed multi-trait meta-analyses of 11 trait categories and a multi-trait meta-analysis that combined all 99 traits to provide a global overview of major QTL segregating in European Brown Swiss cattle. In contrast to Guo et al. [8], we did not analyze the daughter-derived phenotypes from these two populations jointly because we used records that were obtained from distinct national genetic evaluations that differ in trait definitions, scales and base populations. Using multi-trait across country evaluations (MACE) on the national records would provide comparable daughter-derived phenotypes for bulls from different populations $[38,39]$. However, since MACE were not available for the Brown Swiss bulls of our study, we applied a step-wise procedure to consider all animals in our dataset for the association analyses: we first carried out single-trait GWAS for the two populations separately and subsequently combined similar traits in an across-cohort multi-trait meta-analysis. The number of significantly associated SNPs was clearly higher in the trait-category-specific meta-analyses than single-trait GWAS, indicating that this strategy increased the power to detect QTL. Our results corroborate previous findings that multi-trait meta-analysis provides high power to detect QTL, particularly for correlated traits [3, 27, 40]. However, when we combined all 99 single-trait GWAS using a multi-trait meta-analysis, the number of significantly associated SNPs and detected QTL was lower than in the trait-cat meta-analyses. Our results, obtained from a moderately sized mapping population, indicate that the 99-trait meta-analysis had less power than the trait-cat meta-analyses to detect QTL that affect only one trait category. This finding is supported by increased $P$ values for seven out of 12 QTL that were significant in 99-trait meta-analysis but affect only one trait category. Therefore, our results suggest that appropriate clustering of traits with similar definitions or pronounced genetic correlations may provide higher power to detect QTL than meta-analysis of a larger number of (partly) uncorrelated traits.

We detected 25 major QTL $\left(P<8.36 \times 10^{-8}\right)$ affecting economically important traits using 4578 Brown Swiss bulls that had both daughter-derived phenotypes and partially imputed genotypes at 598,016 autosomal SNPs. In spite of a decent sample size and large number of traits with relatively high heritability [41], the number of detected QTL was rather low in our study possibly reflecting a highly polygenic nature of most of the traits considered. It seems likely that most of the economically important traits in Brown Swiss cattle are predominantly determined by many small-effect loci that remained undetected in our study. Our study revealed QTL that explained between 2 and $10 \%$ of the EBV variation. Increasing the marker density, e.g., by imputing sequence variant genotypes might facilitate the fine mapping of the detected QTL [16] and uncover additional QTL that have not been detected using microarray-derived genotypes [42]. However, the markers on the BovineHD Bead chip are likely dense enough to detect QTL in the most popular breeds including Brown Swiss cattle [43]. Substantially increasing the number of genotyped animals seems to be required to detect QTL that explain a smaller proportion of the trait variation in the Brown Swiss cattle. Considering that the population size is considerably smaller in Brown Swiss than Holstein cattle, either applying MACE on progeny-tested animals from distinct populations or including cows with own performance records will increase the size of the mapping populations and thus the power to detect QTL. Moreover, estimating the effects of all markers simultaneously might facilitate to detect QTL with smaller effects [44].

Most of the QTL detected in our study were located nearby QTL that had been described previously in several cattle breeds including Brown Swiss, thus confirming the relevance of these genomic regions for shaping economically important traits in cattle. Most QTL in the 99-trait meta-analysis are associated with milk production, body conformation and, to a lesser extent, calving performance, possibly reflecting that the heritability and thus power to detect associations is higher for production than functional traits. In agreement with findings in Holstein cattle, most of the pleiotropic QTL detected in our study in Brown Swiss cattle were related to body conformation traits $[25,26]$, likely indicating common physiological pathways controlling different body features across cattle breeds. We did not detect pleiotropic QTL that were associated with apparently uncorrelated trait categories, such as milking speed and fertility possibly due to lack of power and stringent significant threshold (Bonferroni correction).

Among 25 detected QTL, five were significantly associated with at least two distinct traits across populations, including QTL at BTA5:93,945,655, BTA6:90,486,780, BTA17:62,697,699, BTA21:913,715 and BTA25:1,455, 150, indicating widespread pleiotropy. A larger mapping population might uncover pleiotropic effects at more QTL. Of these five QTL, those at BTA5:93,945,655, BTA17:62,697,699 and BTA21:913,715 affect several traits in the same trait category, whereas QTL at BTA6: 90,486,780 and BTA25:1,455,150 affect a broad range of traits from different categories. A QTL at BTA5 encompassing the MGST1 gene affects fat percentage, fat yield and protein percentage. Its pleiotropic effects on milk production traits have been shown for several breeds $[11,12]$. The QTL at BTA17:62,697,699 affects rear udder width, fore udder length, front and rear teat placement, and udder cleanness. Its effects on mammary gland morphology have been shown previously in Brown Swiss [9] and Fleckvieh cattle [27]. 
For two QTL (at BTA6:90,486,780 and BTA25:1,455, 150) affecting a broad range of economically important traits, we observed lower $P$ values of the lead SNPs from the 99-trait meta-analysis compared to trait-cat metaanalyses. Such a pattern could indicate that they explain variation in traits from different categories. The QTL at BTA6:90,486,780 affects mammary gland morphology and milking speed. Our results show that this QTL has a larger effect on teat thickness than any other morphological feature of the mammary gland (see Additional file 4: Table S2). This genomic region has previously been identified as a major QTL for mammary gland morphology in Brown Swiss [9], Fleckvieh [27] and Holstein [45] cattle. Our results show that an allele of the lead SNP is associated with thinner teats $\left(P=2.94 \times 10^{-29}\right)$ and reduced milking speed $\left(P=1.96 \times 10^{-12}\right)$, indicating pleiotropic effects that had not been detected so far. It seems plausible that the anatomy of the teat could affect the milking speed, i.e., milk flow is faster in cows with wider teat canal and sphincter [46], which is also shown by the positive correlation between the teat thickness and milking speed [47]. An ideal shape of the mammary gland and an average milking speed are important for efficient machine milking and healthy udders [46, 48, 49]. This implies that bulls with EBVs around the population average are required for the breeding of cows with optimum teat thickness and milking speed. We observed that the cows' teats became thinner within the past 25 years as a part of improving mammary gland morphology in Brown Swiss cattle while the milking speed increased considerably (see Additional file 6: Figure S4 and [50]). The increase in milking speed may result from accumulated positive effects of small-effect QTL that had not been detected in our study. Given that the QTL at BTA6:90,486,780 explains considerably more variation in the EBVs for teat thickness (5\% for Swiss and 7\% for Austrian-German population) than EBVs for milking speed (2\% for Swiss and $0.1 \%$ for Austrian-German population), selecting for the QTL at BTA6:90,486,780 would affect teat thickness to a larger extent than milking speed.

A QTL at BTA25:1,455,150 affects birth weight, body size, gestation length, calving ease and longevity. This QTL has been reported for stature and calving performance in Brown Swiss cattle [8, 10]. Our results show that this QTL also explains variation in longevity and thus might contribute to the overall genetic correlations among stature, calving performance and length of productive life. As shown by the patterns of QTL effects across traits, the allele associated with larger body size and calving difficulties is also associated with longer gestation length. It is likely that this QTL acts on both preand postnatal growth. Enhanced fetal growth may cause dystocia and higher stillbirth incidence, and adult size affects calving abilities of cows [51, 52]. Since the QTL affects both pre- and postnatal growth, selection for an increased adult size and/or birth weight might lead to greater calving difficulties and subsequently higher calf mortality and reduced length of productive life of cows. Nonetheless, traits that are unfavorably correlated with calving performance (such as pre- and postnatal growth) could respond favorably by applying appropriate weights in a selection index or multi-trait BLUP $[53,54]$.

Only one QTL at BTA6:90,486,780 showed evidence of ongoing selection (based on $\mathrm{ROH}$ and iHS statistics). Consistent with previous findings $[55,56]$, we did not detect compelling evidence for the presence of selection signatures around the detected QTL although strong artificial selection particularly on milk production and body conformation traits took place recently in Brown Swiss cattle [50]. Each of the QTL detected in our study explains only a small fraction (less than $5 \%$ except for the one at BTA5:93,945,655) of EBV variation for a given quantitative trait. Moreover, the QTL effects are likely overestimated due to Winner's curse [57]. Therefore, ongoing selection for economically important traits acts on a multitude of genomic regions and is unlikely to change the allele frequency of individual QTL rapidly as shown by the little changes in allele frequencies for the most of lead SNPs at QTL affecting milk production over the past 25 years. Nevertheless, QTL associated with body conformation, which are located at BTA3:120,211,603, BTA5:31,524,629 and BTA25:1,455,150, showed increased homozygosity surrounding the favorable alleles compared to the lead SNPs associated with milk production, confirming recent selection for physical appearance and mammary gland morphology in Brown Swiss cattle, especially for increasing body size and decreasing teat thickness $[20,50,58]$. This is further supported by the observed significant changes in frequency of the favorable alleles of the lead SNPs at four out of six QTL associated with body conformation.

\section{Conclusions}

Here we report an overview of QTL affecting economically important traits in Brown Swiss cattle by applying a multi-trait test statistic. We detected two QTL at BTA6: $90,486,780$ and at BTA25:1,455,150 that affect a broad range of economically important traits, including traits related to body conformation and calving, milking speed and longevity. Furthermore, a QTL at BTA6:90,486,780 showed evidence of ongoing selection, whereas the rest of detected QTL showed no or weak evidence of selection. Our findings provide a comprehensive overview of major QTL that segregate in Brown Swiss cattle and revealed pleiotropic effects that may be relevant for future breeding applications. 


\section{Methods}

\section{Studied populations, phenotypes and genotypes}

We considered genotypes and phenotypes of 4578 Brown Swiss bulls that were used for artificial insemination from Austria, Germany and Switzerland. Estimated breeding values (EBV) and corresponding reliabilities for 56 economically important traits, including milk production, body conformation, carcass and meat quality, health and reproduction (Additional file 1: Table S1) were provided from the Swiss routine genetic evaluation for 1875 bulls and the joint Austrian and German routine genetic evaluation [59] for 2703 bulls. For our association analyses, we considered only bulls that had EBVs with reliabilities greater than 0.4 for all traits.

Of the 4578 bulls, 870 bulls were genotyped with the Illumina HD Bovine SNP chip comprising 777,962 SNPs and 3708 bulls were genotyped using the BovineSNP50 Bead chip (Illumina, San Diego, CA) comprising either 54,001 (version 1) or 54,609 (version 2) SNPs. The physical positions of the SNPs were determined based on the UMD3.1 assembly of the bovine genome [60]. Mitochondrial, Y-chromosomal SNPs and SNPs that had unknown chromosomal position were not considered for the subsequent analyses. Quality control including the exclusion of SNPs and animals with genotyping rates less than $80 \%$ and SNPs showing deviation from the Hardy-Weinberg proportions $(P<0.00001)$ was applied to the $50 \mathrm{~K}$ and HD datasets separately using plink (version 1.9) software [61]. Following quality control, the 50 $\mathrm{K}$ and HD datasets included 3708 and 870 animals, respectively, that had genotypes at 42,649 and 647,091 SNPs. The $50 \mathrm{~K}$ genotypes were imputed to higher density using a combination of Eagle (version 2.4) [62] and Minimac3 (version 2.0.1) [63] as described in Pausch et al. [64]. Following the imputation, our final dataset consisted of 4578 animals that had partially imputed genotypes at 642,196 SNPs. The mean accuracy of imputation ( $\mathrm{r}^{2}$-values from Minimac) was 0.9847. Xchromosomal $(N=15,981)$ SNPs and 28,199 SNPs with minor allele frequency (MAF) less than 1\% were not considered for further analyses, resulting in 598,016 SNPs (mean $\mathrm{r}^{2}$-value from Minimac: 0.9895 ) that were considered for GWAS and selection signature analyses.

\section{Genome-wide association analyses Single-trait association testing}

Analyzing phenotype data from the Swiss and AustrianGerman populations jointly was not readily possible because breeding values for the various phenotypes considered were estimated based on different base populations and thus are not comparable. Moreover, traits may be defined slightly differently in both populations. Thus, we considered the Swiss and Austrian-German populations as two separate cohorts (even for traits had the same name) and performed a total of 99 single-trait GWAS (44 traits in Austrian-German and 55 traits in Swiss population, see Additional file 1: Table S1 for more information about the traits considered).

For each trait considered, single marker-based association studies were carried out using a two-step variance component-based approach that has been implemented using emmax software [65]: $\mathrm{y}=\mu+\mathrm{u}+\mathrm{e}$, where $\mathrm{y}$ is a vector of phenotypes, $\mu$ is the intercept, $u$ is a vector of additive genetic effects $\sim N\left(0, G \sigma_{\mathrm{a}}^{2}\right)$, where $\sigma_{\mathrm{a}}^{2}$ is the additive genetic variance and $\mathrm{G}$ is the genomic relationship matrix built using partly imputed HD genotypes at autosomal SNPs using plink (version 1.9) software [61]. e is a vector of residuals $\sim \mathrm{N}\left(0, \mathrm{I} \sigma_{\mathrm{e}}^{2}\right)$, where $\mathrm{I}$ is the identity matrix and $\sigma_{\mathrm{e}}^{2}$ is the error variance. The allele substitution effect (b) was subsequently obtained from a generalized linear regression model: $y=\mu+x b+\eta$, where $x$ is a vector of genotypes (coded as $0,1,2$ ), and $\eta$ is a vector of random residual deviates with variance $\mathrm{G} \sigma_{\mathrm{a}}^{2}+\mathrm{I} \sigma_{\mathrm{e}}^{2}$.

\section{Multi-trait meta-analysis}

To increase the power of the association tests and characterize pleiotropic QTL, we carried out multi-trait meta-analyses with traits classified into 11 trait categories (referred to as trait-cat meta-analyses). The 11 trait categories were defined according to the classification used at the Interbull Centre (http://www.interbull.org/ ib/geforms), including milk production, body conformation (body size, leg confirmation and mammary gland morphology), reproduction (fertility and calving), and growth and carcass quality. The trait-cat meta-analyses also enabled us to combine traits from the two distinct cohorts, thus possibly increasing the power to detect QTL for traits with similar definitions, such as milking speed, longevity, persistence and somatic cell score. The number of single-trait analyses that were combined using meta-analyses ranged from two (for milking speed, longevity, persistence and somatic cell score) to 26 (for mammary gland morphology; see Additional file 1: Table S1 for the trait classifications).

For each of the 11 trait-cat meta-analysis, a multi-trait chi-squared test for each SNP was performed following the approach proposed by Bolormaa et al. [3] using an approximate test statistics $X_{d f=n}^{2}=t^{\prime}{ }_{i} \mathrm{~V}^{-1} t_{i}$, where $\mathrm{n}$ is the number of traits included in the respective trait category (see Additional file 1: Table S1), $t_{i}$ is a $\mathrm{n} \times 1$ matrix of the signed $\mathrm{t}$-values at the $\mathrm{i}^{\text {th }} \mathrm{SNP}\left(t=\frac{b}{s e(b)}\right)$ across $\mathrm{n}$ traits included ( $b$ is the allele substitution effect and $\mathrm{se}(\mathrm{b})$ is the corresponding standard error obtained from single-trait GWAS), and $\mathrm{V}^{-1}$ is the inverse of the $\mathrm{n} \times \mathrm{n}$ correlation matrix where the correlation between two traits was calculated over the 598,016 estimated SNP effects (signed t-values). 
SNPs with $P$ value less than $8.36 \times 10^{-8}$ (corresponding to a $5 \%$ Bonferroni-corrected significance threshold for 598,016 independent tests) were considered as significantly associated for both single- and multi-trait analyses. QTL regions were defined as one million basepair $(\mathrm{Mb})$ intervals centered on the most significantly associated (lead) SNP. The genes that occur within QTL regions were identified using Ensembl (www.ensembl.org/ biomart/). The proportion of EBV variance explained by a QTL was calculated as $\left(2 \mathrm{pqb}^{2}\right) / \mathrm{V}_{\mathrm{p}}$, where $\mathrm{p}$ and $\mathrm{q}$ are the allele frequencies of the most significantly associated SNP at the respective QTL, $b$ is the allele substitution effect estimated from single-trait GWAS, and $V_{p}$ is the variance of EBV.

\section{Detection of signatures of selection}

Because a principal components analysis of the genomic relationship matrix revealed no separation between the Swiss and Austrian-German populations (see Additional file 7: Figure S5), we considered all animals for the detection of signatures of selection. Genomic regions showing evidence of selection were detected using either runs of homozygosity ( $\mathrm{ROH}$ ) or the integrated haplotype score (iHS) test. To investigate if the detected QTL were under selection, the extended haplotype homozygosity (EHH) was calculated surrounding the lead SNPs of these QTL. To assess changes in QTL frequency over time, allele frequency of the lead SNPs was calculated for the past 25 years based on the birth year of the studied Brown Swiss bulls.

We considered $\mathrm{ROH}$ with minimum length of $2 \mathrm{Mb}$, which are supposed to originate from common ancestors for up to 10-25 generations ago. This corresponds to approximately $50-150$ years assuming an average generation interval of 5-6 years in cattle, to explore the impacts of recent artificial selection for economically important traits $[66,67]$. ROHs that contained at least $50 \mathrm{SNPs}$ and were longer than $2 \mathrm{Mb}$ were identified using a sliding window-based approach implemented in plink (version 1.9) software [61]. Briefly, a sliding window consisting of 50 adjacent SNPs was shifted along all autosomes in steps of one SNP. Two missing genotypes and one heterozygous genotype were allowed within each sliding window. The minimum SNP density within a sliding window was one SNP every $50 \mathrm{~kb}$ to ensure that low SNP density did not confound ROH detection. The maximum gap allowed between two consecutive homozygous SNPs in a ROH was $100 \mathrm{~kb}$. Subsequently, the proportion of individuals with $\mathrm{ROH}$ was calculated for each sliding window. Regions enriched for $\mathrm{ROH}$ were defined as regions with top $1 \%$ of the empirical distribution of the frequency of a SNP occurring in $\mathrm{ROH}$ across individuals.
The EHH-based test statistics, including EHH surrounding the lead SNPs of detected QTL and $|\mathrm{iHS}|$ for each SNP, were calculated according to Sabeti et al. [68] and Voight et al. [69] using $\mathrm{R}$ package rehh [37, 70]. Ancestral and derived alleles were obtained for 539,043 SNPs of Illumina BovineHD Bead chip from Rocha et al. [71], where the ancestral allele was determined as the most frequent allele observed in yak, buffalo and sheep with a minimum of two copies in common across all species to avoid misclassifications due to sequencing errors. Phased haplotypes were obtained using Beagle (version 3.3.2) with 20 iterations of phasing algorithm [72]. The iHS values were standardized within derived allele frequencies bins of 0.02 according to Voight et al. [69]. The $P$ value of the iHS score was derived as $P=1-2 \mid \Phi$ (iHS) $-0.5 \mid$, where $\Phi$ (iHS) is the cumulative Gaussian distribution function of iHS (under neutrality), and $P$ is the two-tailed $P$ value associated with the null hypothesis assuming no selection [73]. The QTL detected in the 99-trait meta-analysis were considered to be under selection if the respective lead SNPs were located in regions containing SNPs with $P<0.001$.

\section{Additional files}

\section{Additional file 1: Table S1. Number of Brown Swiss bulls for 56 economically important traits and their classification. (DOCX 19 kb)}

Additional file 2: Figure S1. Distribution of significant SNPs by number of traits affected for each of 56 economically important traits. (PNG $62 \mathrm{~kb}$ )

Additional file 3: Figure S2. QTL signals detected from milk production, mammary gland morphology and 99-trait meta-analysis on chromosome 6. (PNG 581 kb)

Additional file 4: Table S2. Effects of the lead SNPS at QTL detected from the 99-trait meta-analysis across traits. (XLSX $20 \mathrm{~kb}$ )

Additional file 5: Figure S3. Effects of the lead SNP of the QTL on chromosome 25 across traits. CH: Swiss population; DEU: AustrianGerman population. Effects are t-values estimated from single-trait associations. (PNG $241 \mathrm{~kb}$ )

Additional file 6: Figure S4. Genetic trends for teat thickness and milking speed from year 1980 to 2015. (PNG 232 kb)

Additional file 7: Figure S5. Principle component analysis to evaluate the extent of population structure using genomic relationship matrix comprising 4758 bulls. CH: Swiss population; DEU: Austrian-German population. (PNG $187 \mathrm{~kb}$ )

\section{Abbreviations}

BTA: Bos taurus autosomes; EBV: Estimated breeding values; EHH: Extended haplotype homozygosity; GWAS: Genome-wide association studies; iHS: Integrated haplotype score; LD: Linkage disequilibrium; MACE: Multi-trait across country evaluations; MAF: Minor allele frequency; PCA: Principal component analysis; QTL: Quantitative trait loci; ROH: Runs of homozygosity; SNP: Single nucleotide polymorphism

\section{Acknowledgements}

We acknowledge the Arbeitsgemeinschaft Süddeutscher Rinderzüchter e.V the Arbeitsgemeinschaft Deutsches Braunvieh, Braunvieh Austria, Tierzuchtforschung Grub, Chair of Animal Breeding of TU München, the Institute of Animal Breeding from Bayerische Landesanstalt fuer Landwirtschaft and ZuchtData EDV Dienstleistungen $\mathrm{GmbH}$ for providing genotype and phenotype data for the Austrian and German Brown Swiss 
populations. We thank the Swiss Brown Swiss breeding association (Braunvieh Schweiz), Arbeitsgemeinschaft Schweizerischer Rinderzuechterand Qualitas AG for providing genotype and phenotype data for the Swiss Brown Swiss population.

\section{Authors' contributions}

Analyzed data: Z-HF and HP; Wrote the paper: Z-HF and HP; Read, revised and approved the final version of the paper: Z-HF and HP

\section{Funding}

Not applicable.

\section{Availability of data and materials}

The genotype and phenotype data were provided by breeding organizations (see acknowledgements section) following the execution of material transfer agreements under the condition of strict confidentiality so are not publically available. Contact details of representatives of the breeding organizations are available upon request from Hubert Pausch (hubert.pausch@usys.ethz.ch).

\section{Ethics approval and consent to participate}

Not applicable.

\section{Consent for publication}

Not applicable.

\section{Competing interests}

$\mathrm{HP}$ is a member of the editorial board (Associate Editors) of BMC Genomics.

\section{Received: 15 January 2019 Accepted: 27 August 2019}

Published online: 03 September 2019

\section{References}

1. Hu Z-L, Park CA, Reecy JM. Building a livestock genetic and genomic information knowledgebase through integrative developments of animal QTLdb and CorrDB. Nucleic Acids Res. 2019;47:D701-10.

2. Khansefid M, Pryce JE, Bolormaa S, Miller SP, Wang Z, Li C, et al. Estimation of genomic breeding values for residual feed intake in a multibreed cattle population. J Anim Sci. 2014;92:3270-83.

3. Bolormaa S, Pryce JE, Reverter A, Zhang Y, Barendse W, Kemper K, et al. A multi-trait, meta-analysis for detecting pleiotropic polymorphisms for stature, fatness and reproduction in beef cattle. PLoS Genet. 2014;10: e1004198.

4. Qanbari S, Simianer H. Mapping signatures of positive selection in the genome of livestock. Livest Sci. 2014;166:133-43. https://doi.org/10.1016/j. livsci.2014.05.003.

5. Andersson L, Georges M. Domestic-animal genomics: deciphering the genetics of complex traits. Nat Rev Genet. 2004;5:202-12.

6. Rubin CJ, Zody MC, Eriksson J, Meadows JRS, Sherwood E, Webster MT, et al. Whole-genome resequencing reveals loci under selection during chicken domestication. Nature. 2010:464:587-91.

7. Qanbari S, Pausch H, Jansen S, Somel M, Strom TM, Fries R, et al. Classic selective sweeps revealed by massive sequencing in cattle. PLoS Genet. 2014;10:e1004148.

8. Guo J, Jorjani H, Carlborg Ö. A genome-wide association study using international breeding-evaluation data identifies major loci affecting production traits and stature in the Brown Swiss cattle breed. BMC Genet. 2012;13:82.

9. Flury C, Boschun C, Denzle M, Baps B, Schnyde U, Gredle B, et al. Genomewide association study for 13 udder traits from linear type classification in cattle. In: Proceedings of the 10th world congress of genetics applied to livestock production; 2014.

10. Frischknecht M, Bapst B, Seefried FR, Signer-Hasler H, Garrick D, Stricker C, et al. Genome-wide association studies of fertility and calving traits in Brown Swiss cattle using imputed whole-genome sequences. BMC Genomics. 2017;18:910.

11. Pausch H, Emmerling R, Gredler-Grandl B, Fries R, Daetwyler HD, Goddard ME. Meta-analysis of sequence-based association studies across three cattle breeds reveals 25 QTL for fat and protein percentages in milk at nucleotide resolution. BMC Genomics. 2017;18:853.

12. Littlejohn MD, Tiplady K, Fink TA, Lehnert $K$, Lopdell $T$, Johnson $T$, et al. Sequence-based association analysis reveals an MGST1 eQTL with pleiotropic effects on bovine Milk composition. Sci Rep. 2016;6:25376. https://doi.org/10.1038/srep25376.

13. Kemper KE, Littlejohn MD, Lopdell T, Hayes BJ, Visscher PM, Carrick M, et al. Leveraging genetically simpler traits to identify small-effect variants for complex phenotypes. BMC Genomics. 2016;17:858.

14. Blott S, Kim J-J, Moisio S, Schmidt-Küntzel A, Cornet A, Berzi P, et al. Molecular dissection of a quantitative trait locus: a phenylalanine-to-tyrosine substitution in the transmembrane domain of the bovine growth hormone receptor is associated with a major effect on milk yield and composition. Genetics. 2003;163:253-66.

15. Daetwyler HD, Capitan A, Pausch H, Stothard P, van Binsbergen R, Brøndum RF, et al. Whole-genome sequencing of 234 bulls facilitates mapping of monogenic and complex traits in cattle. Nat Genet. 2014;46:858-65. https:// doi.org/10.1038/ng.3034.

16. Frischknecht M, Pausch H, Bapst B, Signer-Hasler H, Flury C, Garrick D, et al. Highly accurate sequence imputation enables precise QTL mapping in Brown Swiss cattle. BMC Genomics. 2017;18:999.

17. Yang J, Liu X, Wang D, Ning C, Wang H, Zhang Q, et al. Functional validation of GPIHBP1 and identification of a functional mutation in GPIHBP1 for milk fat traits in dairy cattle. Sci Rep. 2017;7:8546. https://doi. org/10.1038/s41598-017-08668-6.

18. Grisart B, Farnir F, Karim L, Cambisano N, Kim J-J, Kvasz A, et al. Genetic and functional confirmation of the causality of the DGAT1 K232A quantitative trait nucleotide in affecting milk yield and composition. Proc Natl Acad Sci U S A. 2004;101:2398-403.

19. Jiang L, Liu X, Yang J, Wang H, Jiang J, Liu L, et al. Targeted resequencing of GWAS loci reveals novel genetic variants for milk production traits. BMC Genomics. 2014;15:1105.

20. Bouwman AC, Daetwyler HD, Chamberlain AJ, Ponce $\mathrm{CH}$, Sargolzaei M, Schenkel FS, et al. Meta-analysis of genome-wide association studies for cattle stature identifies common genes that regulate body size in mammals. Nat Genet. 2018. https://doi.org/10.1038/s41588-018-0056-5.

21. Souquet B, Abby E, Hervé R, Finsterbusch F, Tourpin S, Le Bouffant R, et al. MEIOB targets single-Strand DNA and is necessary for meiotic recombination. PLoS Genet. 2013;9:e1003784.

22. Domene HM, Bengolea SV, Jasper HG, Boisclair YR. Acid-labile subunit deficiency: phenotypic similarities and differences between human and mouse. J Endocrinol Invest. 2005;28(5 Suppl):43-6.

23. Gurrieri F, Everman DB. Clinical, genetic, and molecular aspects of splithand/foot malformation: an update. Am J Med Genet Part A. 2013;161: 2860-72.

24. Lyle R, Radhakrishna U, Blouin JL, Gagos S, Everman DB, Gehrig C, et al. Split-hand/split-foot malformation 3 (SHFM3) at 10q24, development of rapid diagnostic methods and gene expression from the region. Am J Med Genet Part A. 2006:140:1384-95.

25. Cole JB, Wiggans GR, Ma L, Sonstegard TS, Lawlor TJ, Crooker BA, et al. Genome-wide association analysis of thirty one production, health, reproduction and body conformation traits in contemporary U.S. Holstein cows. BMC Genomics. 2011;12:408.

26. Wu X, Fang M, Liu L, Wang S, Liu J, Ding X, et al. Genome wide association studies for body conformation traits in the Chinese Holstein cattle population. BMC Genomics. 2013;14:897.

27. Pausch $\mathrm{H}$, Emmerling $\mathrm{R}$, Schwarzenbacher $\mathrm{H}$, Fries R. A multi-trait metaanalysis with imputed sequence variants reveals twelve QTL for mammary gland morphology in Fleckvieh cattle. Genet Sel Evol. 2016;48:14. https://doi. org/10.1186/s12711-016-0190-4.

28. Pausch H, Flisikowski K, Jung S, Emmerling R, Edel C, Götz KU, et al. Genome-wide association study identifies two major loci affecting calving ease and growth-related traits in cattle. Genetics. 2011;187:289-97.

29. Schwarzenbacher $H$, Burgstaller J, Seefried FR, Wurmser C, Hilbe M, Jung $S$, et al. A missense mutation in TUBD1 is associated with high juvenile mortality in Braunvieh and Fleckvieh cattle. BMC Genomics. 2016;17:400. https://doi.org/10.1186/s12864-016-2742-y.

30. Scholz B, Korn C, Wojtarowicz J, Mogler C, Augustin I, Boutros M, et al. Endothelial RSPO3 controls vascular stability and pruning through noncanonical WNT/Ca2+/NFAT signaling. Dev Cell. 2016;36:79-93. https://doi. org/10.1016/j.devcel.2015.12.015.

31. Woods L, Perez-Garcia V, Hemberger M. Regulation of placental development and its impact on fetal growth — new insights from mouse models. Front Endocrinol (Lausanne). 2018;9:570. https://doi.org/10.3389/ fendo.2018.00570 
32. Mao X, Sahana G, De Koning D-J, Guldbrandtsen B. Genome-wide association studies of growth traits in three dairy cattle breeds using whole-genome sequence data. J Anim Sci. 2016;94:1426. https://doi.org/10.2527/jas.2015-9838.

33. Heine PA, Taylor JA, Iwamoto GA, Lubahn DB, Cooke PS. Increased adipose tissue in male and female estrogen receptor-alpha knockout mice. Proc Natl Acad Sci. 2000;97:12729-34. https://doi.org/10.1073/pnas.97.23.12729.

34. Öz OK, Millsaps R, Welch R, Birch J, Zerwekh JE. Expression of aromatase in the human growth plate. J Mol Endocrinol. 2001;27:249-53.

35. Jardim JG, Guldbrandtsen B, Lund MS, Sahana G. Association analysis for udder index and milking speed with imputed whole-genome sequence variants in Nordic Holstein cattle. J Dairy Sci. 2017;101:2199-212. https://doi. org/10.3168/jds.2017-12982.

36. Utsunomiya YT, Pérez O'Brien AM, Sonstegard TS, Van Tassell CP, do Carmo AS, Mészáros $\mathrm{G}$, et al. Detecting loci under recent positive selection in dairy and beef cattle by combining different genome-wide scan methods. PLoS One. 2013;8:e64280

37. Gautier M, Klassmann A, Vitalis R. Rehh 2.0: a reimplementation of the $R$ package rehh to detect positive selection from haplotype structure. Mol Ecol Resour. 2017:17:78-90.

38. Schaeffer LR. Multiple-country comparison of dairy sires. J Dairy Sci. 1994;77: 2671-8. https://doi.org/10.3168/jds.S0022-0302(94)77209-X.

39. Fikse WF, Banos G. Weighting factors of sire daughter information in international genetic evaluations. J Dairy Sci. 2001:84:1759-67. https://doi. org/10.3168/jds.S0022-0302(01)74611-5.

40. Liu A, Wang Y, Sahana G, Zhang Q, Liu L, Lund MS, et al. Genomewide association studies for female fertility traits in Chinese and Nordic Holsteins. Sci Rep. 2017;7:8487.

41. Goddard ME, Hayes BJ. Mapping genes for complex traits in domestic animals and their use in breeding programmes. Nat Rev Genet. 2009;10: 381-91. https://doi.org/10.1038/nrg2575.

42. Yan G, Qiao R, Zhang F, Xin W, Xiao S, Huang T, et al. Imputation-based whole-genome sequence association study rediscovered the missing QTL for lumbar number in Sutai pigs. Sci Rep. 2017;7:615. https://doi.org/10.103 8/s41598-017-00729-0.

43. Matukumalli LK, Lawley CT, Schnabel RD, Taylor JF, Allan MF, Heaton MP, et al. Development and characterization of a high density SNP genotyping assay for cattle. PLoS One. 2009;4:e5350.

44. MacLeod IM, Bowman PJ, Vander Jagt CJ, Haile-Mariam M, Kemper KE, Chamberlain AJ, et al. Exploiting biological priors and sequence variants enhances QTL discovery and genomic prediction of complex traits. BMC Genomics. 2016;17:144. https://doi.org/10.1186/s12864-016-2443-6.

45. Hiendleder S, Thomsen H, Reinsch N, Bennewitz J, Leyhe-Horn B, Looft C, et al. Mapping of QTL for body conformation and behavior in cattle. J Hered. 2003;94: 496-506.

46. Blake RW, McDaniel BT. Relationships of udder conformation with labor and machine inputs to Milk harvest in dairy cattle. J Dairy Sci. 1979;62:475-85. https://doi.org/10.3168/jds.S0022-0302(79)83269-5.

47. Weiss D, Weinfurtner M, Bruckmaier RM. Teat anatomy and its relationship with quarter and udder Milk flow characteristics in dairy cows. J Dairy Sci. 2004;87:3280-9. https://doi.org/10.3168/jds.S0022-0302(04)73464-5.

48. Boettcher PJ, Dekkers JCM, Kolstad BW. Development of an udder health index for sire selection based on somatic cell score, udder conformation, and milking speed. J Dairy Sci. 1998;81:1157-68. https:// doi.org/10.3168/jds.S0022-0302(98)75678-4.

49. Rupp R, Boichard D. Genetic parameters for clinical mastitis, somatic cell score, production, udder type traits, and milking ease in first lactation Holsteins. J Dairy Sci. 1999;82:2198-204. https://doi.org/10.316 8/jds.S0022-0302(99)75465-2.

50. Braunvieh Schweiz. Genetische trends beim Schweizer Braunvieh; 2018. https://homepage.braunvieh.ch/xml_1/internet/de/application/d7/d1163/ f561.cfm. Accessed 15 Sep 2018

51. Hansen M, Lund MS, Pedersen J, Christensen LG. Gestation length in Danish Holsteins has weak genetic associations with stillbirth, calving difficulty, and calf size. Livest Prod Sci. 2004;91:23-33.

52. Eaglen S, Coffey M, Woolliams J, Wall E. Direct and maternal genetic relationships between calving ease, gestation length, milk production, fertility, type, and lifespan of Holstein-Friesian primiparous cows. J Dairy Sci. 2013;96:4015-25. https://doi.org/10.3168/jds.2012-6229.

53. Bennett GL. Experimental selection for calving ease and postnatal growth in seven cattle populations. I. Changes in estimated breeding values. J Anim Sci. 2008;86:2093-102.
54. Bennett GL, Thallman RM, Snelling WM, Kuehn LA. Experimental selection for calving ease and postnatal growth in seven cattle populations. II phenotypic differences. J Anim Sci. 2008;86:2103-14.

55. Kemper KE, Saxton SJ, Bolormaa S, Hayes BJ, Goddard ME. Selection for complex traits leaves little or no classic signatures of selection. BMC Genomics. 2014;15:246.

56. Kemper KE, Hayes BJ, Daetwyler HD, Goddard ME. How old are quantitative trait loci and how widely do they segregate? J Anim Breed Genet. 2015;132:121-34.

57. Palmer C, Pe'er I. Statistical correction of the Winner's curse explains replication variability in quantitative trait genome-wide association studies. PLoS Genet. 2017;13(7):e1006916.

58. Krogmeier D. Zusammenhänge zwischen nutzungsdauer und körpergröße unter besonderer berücksichtigung des stallsystems bei Braunvieh und Fleckvieh. Zuchtungskunde. 2009;81:328-40.

59. Emmerling R, Lidauer M, Mäntysaari EA. Multiple lactation random regression test-day model for Simmental and Brown Swiss in Germany and Austria. In: Proceedings of the 2002 Interbull meeting; 2002. p. 111-7.

60. Zimin AV, Delcher AL, Florea L, Kelley DR, Schatz MC, Puiu D, et al. A wholegenome assembly of the domestic cow, Bos taurus. Genome Biol. 2009;10:R42.

61. Chang CC, Chow CC, Tellier LCAM, Vattikuti S, Purcell SM, Lee JJ. Secondgeneration PLINK: rising to the challenge of larger and richer datasets. Gigascience. 2015;4:7.

62. Loh P-R, Danecek P, Palamara PF, Fuchsberger C, Reshef YA, Finucane HK, et al. Reference-based phasing using the haplotype reference consortium panel. Nat Genet. 2016;48:1443.

63. Das S, Forer L, Schönherr S, Sidore C, Locke AE, Kwong A, et al. Next-generation genotype imputation service and methods. Nat Genet. 2016;48:1284.

64. Pausch H, MacLeod IM, Fries R, Emmerling R, Bowman PJ, Daetwyler HD, et al. Evaluation of the accuracy of imputed sequence variant genotypes and their utility for causal variant detection in cattle. Genet Sel Evol. 2017;49:24.

65. Kang HM, Sul JH, Service SK, Zaitlen NA, Kong S, Freimer NB, et al. Variance component model to account for sample structure in genome-wide association studies. Nat Genet. 2010;42:348.

66. Ferenčaković M, Hamzić E, Gredler B, Solberg TR, Klemetsdal G, Curik I, et al. Estimates of autozygosity derived from runs of homozygosity: empirical evidence from selected cattle populations. J Anim Breed Genet. 2013;130:286-93

67. Kim ES, Cole JB, Huson H, Wiggans GR, Van Tassel CP, Crooker BA, et al. Effect of artificial selection on runs of homozygosity in U.S. Holstein cattle. PLoS One. 2013;8:e80813.

68. Sabeti PC, Reich DE, Higgins JM, Levine HZP, Richter DJ, Schaffner SF, et al. Detecting recent positive selection in the human genome from haplotype structure. Nature. 2002;419:832-7. https://doi.org/10.1038/nature01027.1.

69. Voight BF, Kudaravalli S, Wen X, Pritchard JK. A map of recent positive selection in the human genome. PLoS Biol. 2006;4:e72.

70. R Core Team. R: a language and environment for statistical computing. ViennaURL http://www.R-project.org: R Foundation for Statistical Computing; 2015.

71. Rocha D, Billerey C, Samson F, Boichard D, Boussaha M. Identification of the putative ancestral allele of bovine single-nucleotide polymorphisms. J Anim Breed Genet. 2014;131:483-6.

72. Browning SR, Browning BL. Rapid and accurate haplotype phasing and missing-data inference for whole-genome association studies by use of localized haplotype clustering. Am J Hum Genet. 2007;81:1084-97. https:// doi.org/10.1086/521987

73. Gautier M, Naves M. Footprints of selection in the ancestral admixture of a New World creole cattle breed. Mol Ecol. 2011;20:3128-43.

\section{Publisher's Note}

Springer Nature remains neutral with regard to jurisdictional claims in published maps and institutional affiliations. 